Supporting Information

\title{
Solvent-free Reactions with Hypervalent Iodine Reagents
}

\author{
Mekhman S. Yusubov ${ }^{*}, \dagger$ and Thomas Wirth ${ }^{*, *}$ \\ ${ }^{\dagger}$ Department of Chemistry, Siberian State Medical University, Moskovski trakt, 2, 634050 \\ Tomsk, Russia, Department of Organic Chemistry, Tomsk Polytechnic University, 30 Lenin \\ st., 634050 Tomsk, Russia, and \\ ${ }^{\ddagger}$ School of Chemistry, Cardiff University, P.O. Box 912, Cardiff CF10 3TB, UK
}

yusubov@mail.ru,wirth@cf.ac.uk

General Procedure for the Synthesis of Products 3a and $\mathbf{3 c}-\mathbf{3 f}$ :

A mixture of (diacetoxyiodo)arene $1(0.571 \mathrm{mmol})$ and sulfonic acid (3a, 3e: paratoluenesulfonic acid monohydrate $2 \mathbf{a}, 111 \mathrm{mg}, 0.584 \mathrm{mmol} ; \mathbf{3 c}, 3 \mathbf{d}, \mathbf{3 f}$ : (1R)-10-

camphorsulfonic acid $2 \mathbf{c}, 135 \mathrm{mg}, 0.581 \mathrm{mmol}$ ) was gently blended in an agate mortar. The resulting homogeneous mixture was then ground for $10 \mathrm{~min}$. The formation of acetic acid and wetting of the reaction mixture was observed. The solid residue was washed with diethyl ether $(5 \mathrm{~mL})$ and dried under high vacuum to afford the product $\mathbf{3}$ in yields descibed in Table 1.

Procedure for the Synthesis of Product 3b:

Methanesulfonic acid $\mathbf{2 b}(92 \mathrm{mg}, 0.96 \mathrm{mmol})$ and (diacetoxyiodo)benzene 1a (302 mg, 0.94 $\mathrm{mmol}$ ) was placed in an agate mortar and intensively grinded. The formation of acetic acid was observed and the reaction mass turned yellow. After approximately $1 \mathrm{~min}$ the color of the reaction mixture changed to white and the formation of white crystals was observed. The grinding was continued for $10 \mathrm{~min}$. The product was dried in high vacuum to remove the residue of acetic acid and methanesulfonic acid to yield 3b (292 mg, 98\%). The water required for the formation of the hydroxysulfonate derivative is believed to come from the air.

Procedure for the Synthesis of Product 6a from 4:

Iodosyl benzoic acid 4 (136 mg, $0.515 \mathrm{mmol})$, para-toluenesulfonic acid monohydrate 2a $(100 \mathrm{mg}, 0.526 \mathrm{mmol})$ and two drops of acetic acid were added to the mixture before the beginning of grinding $(10 \mathrm{~min})$ in order to soften the reaction mixture. The solid residue was washed with diethyl ether $(5 \mathrm{~mL})$ and dried under high vacuum to afford the product $6 \mathbf{6}(212$ mg, 91\%).

Procedure for the Synthesis of Product $6 \mathbf{b}$ from 4:

Methanesulfonic acid $\mathbf{2 b}(52 \mathrm{mg}, 0.54 \mathrm{mmol})$ and iodosyl benzoic acid 4 (141 mg, 0.534 $\mathrm{mmol}$ ) was placed in an agate mortar and intensively ground. The grinding was continued for $10 \mathrm{~min}$. The product was dried under high vacuum to yield $\mathbf{6 b}(196 \mathrm{mg}, 86 \%)$.

Procedure for the Synthesis of Product 6a from 5:

A mixture of (diacetoxyiodo)benzene 1a (164 mg, $0.509 \mathrm{mmol})$ and 2-iodobenzoic acid 5 (126 mg, $0.508 \mathrm{mmol}$ ) was gently blended in an agate mortar and ground for $10 \mathrm{~min}$. There is no reaction occuring. para-Toluenesulfonic acid monohydrate $\mathbf{2 a}(95 \mathrm{mg}, 0.5 \mathrm{mmol})$ was added and grinding was continued for $10 \mathrm{~min}$. The solid residue was washed with diethyl ether $(5 \mathrm{~mL})$ and dried under high vacuum to afford the product $6 \mathbf{a}(198 \mathrm{mg}, 86 \%)$. 
Procedure for the Synthesis of Product $6 \mathbf{b}$ from 5:

Methanesulfonic acid 2b (93 mg, $0.968 \mathrm{mmol}$ ), (diacetoxyiodo)benzene 1a (310 mg, 0.96 $\mathrm{mmol})$ and 2-iodobenzoic acid $(239 \mathrm{mg}, 0.96 \mathrm{mmol})$ were gently blended in an agate mortar and ground for $10 \mathrm{~min}$. The solid residue was washed with diethyl ether $(5 \mathrm{~mL})$ and dried under high vacuum to afford the product $\mathbf{6 b}(342 \mathrm{mg}, 80 \%)$.

General Procedure for the Sulfonylation of Ketones / Alkenes:

Hydroxy(tosyloxy)iodobenzene 3a (or a mixture of (diacetoxyiodo)benzene 1a and paratoluenesulfonic acid monohydrate $\mathbf{2 a}$ ) or hydroxy(methansulfonyl)iodobenzene $\mathbf{3 b}$ (or a mixture of (diacetoxyiodo)benzene 1a and methanesulfonic acid $\mathbf{2 b}$ ) and the corresponding ketone / alkene was ground in an agate mortar for $10 \mathrm{~min}$. The resulting mass formed a thin layer on the surface of the mortar. All this mass was moved to the center of the mortar's bottom and the grinding was repeated for $10 \mathrm{~min}$. The reaction mixture was dried under high vacuum, and the residue washed with a small amount of diethyl ether.

Table 3, Entry 1: The product is an oil and consequently the yield was not high after washing with diethyl ether.

Table 3, Entry 2: White crystals, recrystallization from $\mathrm{MeOH}$.

Table 3, Entries 5 and 6: Purification by flash chromatography.

Table 3, Entry 13: Purification by recrystallization from $\mathrm{MeOH}-\mathrm{H}_{2} \mathrm{O}$. 